\title{
Female patients with atrial fibrillation have increased oxidized and glycated lipoprotein properties and lower apolipoprotein A-I expression in HDL
}

\author{
SEONG-MIN KIM ${ }^{1 *}$, JI-HYE LEE ${ }^{1 *}$, JAE-RYONG KIM $^{2}$, DONG-GU SHIN ${ }^{3,4}$, \\ SANG-HEE LEE $^{3}$ and KYUNG-HYUN CHO ${ }^{1,4}$
}

\begin{abstract}
${ }^{1}$ School of Biotechnology, Aging-Associated Vascular Disease Research Center, Yeungnam University, Gyeongsan 712-749; ${ }^{2}$ Department of Biochemistry and Molecular Biology, Aging-Associated Vascular Disease

Research Center, Yeungnam University; ${ }^{3}$ Cardiovascular Division, Internal Medicine, Aging-Associated

Vascular Disease Research Center, Yeungnam University Medical Center, Daegu 705-717;

${ }^{4}$ Research Institute of Protein Sensor, Yeungnam University, Gyeongsan 712-749, Republic of Korea
\end{abstract}

Received October 15, 2010; Accepted November 24, 2010

DOI: $10.3892 /$ ijmm.2011.646

\begin{abstract}
It is well-known that oxidative stress and inflammatory processes are linked to the incidence of atrial fibrillation (AF). In order to provide prognostic biomarkers for AF based on lipoprotein levels, we compared the lipid and protein parameters of oxidation and inflammation in individual lipoproteins from middle-aged females with AF. We analyzed plasma and lipoproteins (VLDL, LDL, $\mathrm{HDL}_{2}, \mathrm{HDL}_{3}$ ) from 11 female patients (mean age, $56 \pm 15$ years) with paroxysmal lone $\mathrm{AF}$ and from a reference group of 10 female patients of similar age (mean age, $54 \pm 15$ years). The AF group had normal levels of serum lipids and an inflammatory profile, except for a 7.5- and 6-fold elevation in hsCRP and tropoinin I levels, respectively. No significant differences existed in serum lipids, glucose, uric acid, creatinine and blood urea nitrogen levels between the AF and control groups. The lipoprotein particles from the AF group were more oxidized and glycated with higher triacylglycerol content compared to the control group and the particle size was smaller. The lipoprotein particles from the AF group promoted more foam cell formation via accelerated phagocytosis by macrophages compared to the control group. $\mathrm{HDL}_{2}$ and $\mathrm{HDL}_{3}$ from the $\mathrm{AF}$ group showed decreased antioxidant ability and an approximately $30 \%$ lower expression of apoA-I compared to the control group. All of these modified properties of lipoproteins, including oxidation and glycation, might be linked to the lower antioxidant ability and elevated inflammatory parameters in women with AF.
\end{abstract}

Correspondence to: Dr Kyung-Hyun Cho, School of Biotechnology, Yeungnam University, Gyeongsan 712-749, Republic of Korea E-mail: chok@yu.ac.kr

*Contributed equally

Key words: atrial fibrillation, lipoprotein, apolipoprotein A-I, oxidation, inflammation, glycation

\section{Introduction}

Atrial fibrillation (AF) is the most common arrhythmia in adults. An increased prevalence of AF is anticipated with the increase in the aging population and survivability of patients with chronic heart disease (1). A growing body of evidence implicates oxidative stress in the pathogenesis and perpetuation of AF (2-4). These findings were primarily derived from studies of animal and human samples with persistent or permanent forms of AF. In addition, it is still unclear if the abnormalities observed in these studies are the basis for the arrhythmia or are a consequence of the arrhythmia itself, particularly with respect to paroxysmal lone AF.

Oxidative modification of lipoproteins is regarded as a key step in the formation of atherosclerosis (5). In addition, lipid peroxidation induces cell damage in cardiac myocytes and electrophysiologic alterations, including generation of after-depolarizations and modification of transmembrane ion currents (6-8). Thus, it has been postulated that decreased antioxidative function, which might be present in paroxysmal $\mathrm{AF}$ and a consequence of increased lipid peroxidation, would provide the AF predisposing substrate. Furthermore, rapid atrial pacing or atrial tachyarrhythmias contribute to the increased expression of oxidative stress markers and electrophysiologic changes in the atria $(4,9)$. In this study, we evaluated the composition and function of lipoproteins with respect to oxidation and inflammation in patients with paroxysmal lone AF, remote in time from arrhythmias to exclude the remodeling effects of the arrhythmia itself.

Dyslipidemia is an important risk factor for cardiovascular disease (CVD) and low-density lipoprotein-cholesterol (LDL-C) is a strong biomarker predictive of the risk of CVD (10). Patients with diabetes and metabolic syndrome have a strong association with atherogenic dyslipidemia, which includes high triacylglycerides (TG) and elevated small dense LDL (11). However, the patients with AF in this study and other studies (12) have a lipid profile in the normal range based on NCEP ATP III guidelines (13), indicating that a 
different pathological mechanism might be involved in the development of AF. To overcome this discrepancy between the serum lipid profile and the pathophysiology of AF, the composition and function of lipoproteins should be investigated. The antioxidant ability of serum is highly dependent on the extent of LDL oxidation and the capability of HDL to exert anti-inflammatory activity (14).

HDL exerts many beneficial effects for the maintenance of a healthy physiological system, including antioxidant, anti-inflammatory and anti-thrombotic effects $(15,16)$. These activities are exerted in accordance with the composition of essential apolipoproteins and associated enzymes.

This study was designed to compare individual lipoprotein properties between female patients with $\mathrm{AF}$ and gender- and age-matched controls to provide distinct biomarkers in apolipoprotein and lipoprotein metabolism. To identify unique properties in lipoprotein levels regarding oxidation and inflammation, we isolated lipoproteins from middle-aged females with AF by sequential ultracentrifugation.

\section{Materials and methods}

Patients. This study was comprised of 11 female patients (mean age, 56 \pm 15 years) with paroxysmal lone AF and a reference group of 10 female patients of similar age (mean age, $54 \pm 15$ years). The reference patients had structurally normal hearts and were undergoing radiofrequency ablation for atrioventricular nodal reentrant tachycardia with no history of AF. Paroxysmal AF was defined according to the Executive Summary on Practice Guidelines as recurrent AF that terminates spontaneously within 7 days (17). Patients were excluded from the study group if they had AF during the week before enrollment (confirmed by continuous monitoring) and if they had a medical history or clinical evidence of systemic diseases, such as hypertension, hyperthyroidism, and diabetes. The absence of structural heart disease or coronary artery disease (CAD) was confirmed based on history, physical examination, chest X-ray, routine blood chemistry, exercise stress test, and transthoracic and transesophageal echocardiography, if needed. All anti-arrhythmic medications or statins for the treatment of dyslipidemia were not used before the study. All patients provided written informed consent. The study protocol was approved by the Institutional Review Board at the Yeungnam University Medical Center in Daegu, Republic of Korea.

Echocardiography. Two-dimension and Doppler echocardiographies were performed by one experienced sonographer using a GE Vivid 4 System (GPS Medical, Indianapolis, IN, USA) at the time of sampling. Left ventricular end-diastolic diameter and left atrial (LA) dimension were measured by M-mode-derived anteroposterior linear dimension from the parasternal long axis view as recommended by the American Society of Echocardiography. The left ventricular ejection fraction (LVEF) was calculated using a modified Simpson rule.

Plasma analysis. Blood was obtained following an overnight fast from AF patients and controls. Blood was collected using a vacutainer (BD Biosciences, Franklin Lakes, NJ, USA) containing EDTA (final concentration, $1 \mathrm{mM}$ ). Plasma was isolated by low-speed centrifugation and stored at $-80^{\circ} \mathrm{C}$ until analysis. Blood parameters, lipids, and glucose concentrations were determined using an automatic blood analyzer (Chemistry Analyzer AU4500; Olympus, Tokyo, Japan).

Isolation and characterization of lipoproteins. Very low-density lipoproteins (VLDL, $\mathrm{d}<1.019 \mathrm{~g} / \mathrm{ml})$, LDL $(1.019<\mathrm{d}<1.063)$, $\mathrm{HDL}_{2}(1.063<\mathrm{d}<1.125)$, and $\mathrm{HDL}_{3}(1.125<\mathrm{d}<1.225)$ were isolated from individual patient and control sera via sequential ultracentrifugation (18), with the density adjusted by the addition of $\mathrm{NaCl}$ and $\mathrm{NaBr}$ in accordance with standard protocols. Samples were centrifuged at $100,000 \mathrm{x}$ g for $24 \mathrm{~h}$ at $10^{\circ} \mathrm{C}$ using a Himac CP-90 $\alpha$ (Hitachi, Tokyo, Japan).

For each of the lipoproteins which were individually purified, total cholesterol (TC) and triglycerides (TG) measurements were obtained using commercially available kits (T-CHO and Cleantech TS-S; Wako Pure Chemical, Osaka, Japan). The protein concentrations of lipoproteins were determined via the Lowry protein assay, as modified by Markwell et al (19) using the Bradford assay reagent (Bio-Rad, Seoul, South Korea) with bovine serum albumin (BSA) as a standard. To assess the degree of oxidation of individual LDL, the concentration of oxidized species in LDL (oxLDL) was determined by the thiobarbituric acid reactive substances (TBARS) method using malondialdehyde (MDA) as a standard (20).

To compare the extent of glycation between the groups, the content of advanced glycation end products (AGEs) in the individual lipoproteins were determined from reading the fluorometric intensities at $370 \mathrm{~nm}$ (excitation) and $440 \mathrm{~nm}$ (emission), as described recently by our research group (21).

Copper-mediated LDL-oxidation. To compare the susceptibility of copper-mediated LDL oxidation, $300 \mu \mathrm{g}$ of LDL were incubated with $5 \mu \mathrm{M} \mathrm{CuSO}_{4}$ for up to $3 \mathrm{~h}$. During the incubation, the quantity of formed conjugated dienes was monitored by measuring the absorbance at $234 \mathrm{~nm}\left(\mathrm{Abs}_{234}\right)$ at $37^{\circ} \mathrm{C}$ (22) using a Beckman DU800 spectrophotometer (Beckman Coulter, Fullerton, CA, USA) equipped with a MultiTemp III thermocirculator (Amersham, Uppsala, Sweden).

In order to verify the spectroscopic data, the oxLDL samples were subjected to electrophoresis on a $0.5 \%$ agarose gel for an electromobility comparison (23). The post-oxidative electrophoretic mobility of LDL was compared via electrophoresis on a $0.5 \%$ agarose gel because there is some modification of amino acids in apo-B by oxidation.

Ferric-reducing ability of plasma assay. The ferric-reducing ability of plasma (FRAP) was determined using the method described by Benzie and Strain (24) with a slight modification, as described recently by our research group (25).

Briefly, the FRA reagents were freshly prepared by mixing $25 \mathrm{ml}$ of $0.2 \mathrm{M}$ acetate buffer (pH 3.6), $2.5 \mathrm{ml}$ of $10 \mathrm{mM} \mathrm{2,4,6,}$ tripyridyl-s-triazine (TPTZ; Fluka Chemicals), and $2.5 \mathrm{ml}$ of $20 \mathrm{mM} \mathrm{FeCl}{ }_{3} \cdot 6 \mathrm{H}_{2} \mathrm{O}$. The antioxidant activities of $\mathrm{HDL}_{3}$ were then estimated by measuring the increase in absorbance induced by the generated ferrous ions. The freshly prepared FRA reagent $(300 \mu \mathrm{l})$ was mixed with equally diluted $\mathrm{HDL}_{3}$ $(2 \mathrm{mg} / \mathrm{ml}, 10 \mu \mathrm{l})$, which was dialyzed extensively against PBS, after which the FRA was determined by measuring the absorbance at $593 \mathrm{~nm}$ every $20 \mathrm{sec}$ over a 10 -min period 
Table I. Plasma profiles of AF patients and controls.

\begin{tabular}{|c|c|c|}
\hline & $\begin{array}{c}\text { AF } \\
(n=11)\end{array}$ & $\begin{array}{l}\text { Control } \\
(n=10)\end{array}$ \\
\hline Age (years) & $56.6 \pm 15.9$ & $54 \pm 15.5$ \\
\hline BMI $\left(\mathrm{kg} / \mathrm{m}^{2}\right)$ & $24.3 \pm 3.6$ & $23.4 \pm 3.4$ \\
\hline $\mathrm{SBP}(\mathrm{mmHg})$ & $117 \pm 18.9$ & $116.4 \pm 11.1$ \\
\hline $\mathrm{DBP}(\mathrm{mmHg})$ & $74.9 \pm 14.5$ & $72 \pm 8.3$ \\
\hline $\operatorname{LVEF}(\%)$ & $63 \pm 6$ & $64 \pm 4$ \\
\hline LA size (mm) & $34.3 \pm 7.3$ & $31.1 \pm 4.5$ \\
\hline $\mathrm{TC}(\mathrm{mg} / \mathrm{dl})$ & $200.8 \pm 33.1$ & $188.7 \pm 30.7$ \\
\hline TG (mg/dl) & $113.9 \pm 81.2$ & $168.5 \pm 77.3$ \\
\hline HDL-C (mg/dl) & $59 \pm 13.1$ & $53 \pm 18.2$ \\
\hline$\% \mathrm{HDL}$ in $\mathrm{TC}$ & $29 \pm 9$ & $28 \pm 5$ \\
\hline LDL-C & $119.6 \pm 35.7$ & $110.8 \pm 21.1$ \\
\hline TC/HDL ratio & $3.6 \pm 1$ & $3.8 \pm 0.9$ \\
\hline LDL/HDL ratio & $2.2 \pm 0.8$ & $2.2 \pm 0.7$ \\
\hline GOT (U/1) & $30.5 \pm 20.1$ & $24 \pm 5$ \\
\hline GPT (U/l) & $20.1 \pm 9.7$ & $16.9 \pm 2.9$ \\
\hline TSH (U/l) & $2.3 \pm 2$ & $2.5 \pm 0.9$ \\
\hline hsC-reactive protein $(\mathrm{mg} / \mathrm{l})$ & $0.3 \pm 0.4^{\mathrm{a}}$ & $0.04 \pm 0.04$ \\
\hline Glucose (mg/dl) & $113.5 \pm 30.1$ & $113.3 \pm 31.4$ \\
\hline Uric acid (mg/dl) & $4.9 \pm 2$ & $3.4 \pm 1$ \\
\hline Blood urea nitrogen (mg/dl) & $14.7 \pm 6.9$ & $14.6 \pm 3.1$ \\
\hline Creatinine (mg/dl) & $0.8 \pm 0.3$ & $0.7 \pm 0.1$ \\
\hline Troponin I (ng/ml) & $0.3 \pm 0.6^{\mathrm{a}}$ & $0.05 \pm 0.04$ \\
\hline CETP activity (\% CE-transfer) & $25 \pm 1$ & $26 \pm 2$ \\
\hline
\end{tabular}

BMI, body mass index; SBP, systolic blood pressure; DBP, diastolic blood pressure; LVEF, left ventricular ejection fraction; LA, left atrium; C, cholesterol; CETP, cholesteryl ester transfer protein; GOT, glutamic oxaloacetic transaminase; GPT, $\gamma$-glutamic pyruvic transaminase; TSH, thyroid stimulating hormone; HDL, high-density lipoprotein, LDL, low-density lipoprotein. TC, total cholesterol; TG, triglyceride; VLDL, very-low-density lipoprotein; ${ }^{\mathrm{a}} \mathrm{p}<0.05$ vs. control.

at $25^{\circ} \mathrm{C}$ using a DU800 spectrophotometer equipped with a MultiTemp III thermocirculator.

Cholesteryl ester transfer assay. A reconstituted HDL (rHDL)containing apoA-I and cholesteryl oleate was synthesized in accordance with the method described by Cho et al (26) using trace amounts of $\left[{ }^{3} \mathrm{H}\right]$-cholesteryl oleate (TRK886, $3.5 \mu \mathrm{Ci} / \mathrm{mg}$ of apoA-I; GE Healthcare) as a CE-donor. Next, to facilitate separation from the CE-acceptor, the rHDL was immobilized using a CNBr-activated Sepharose 4B resin (Amersham Biosciences), according to the manufacturer's instructions.

The CE-transfer reaction was allowed in $300 \mu 1$ reaction mixtures that contained each of the serum samples $(20 \mu \mathrm{l})$ as a cholesteryl ester transfer protein (CETP) source, rHDL-agarose (50 $\mu 1,0.25 \mathrm{mg} / \mathrm{ml})$, and human LDL $(50 \mu 1,0.25 \mathrm{mg} / \mathrm{ml})$ as a cholesteryl (CE)-donor and -acceptor, respectively. After incubation for $6 \mathrm{~h}$ at $37^{\circ} \mathrm{C}$, the reaction was halted via brief centrifugation $(10,000 \mathrm{x} \mathrm{g})$ for $3 \mathrm{~min}$ at $4^{\circ} \mathrm{C}$. The supernatant, which contained the CE-acceptor $(150 \mu \mathrm{l})$, was then subjected to scintillation counting, and the percentage transfer of $\left[{ }^{3} \mathrm{H}\right]-\mathrm{CE}$ from $\mathrm{rHDL}$ to LDL was calculated.

Paraoxonase assay. Paraoxonase-1 (PON-1) activity toward paraoxon was determined by evaluating the hydrolysis of paraoxon into p-nitrophenol and diethylphosphate, which was catalyzed by the enzyme (27). PON-1 activity was then determined by measuring the initial velocity of p-nitrophenol production at $37^{\circ} \mathrm{C}$ by measuring the absorbance at $405 \mathrm{~nm}$ (microplate reader, Bio-Rad model 680; Bio-Rad, Hercules, CA, USA).

Western blot analysis. The apolipoprotein/lipoprotein compositions were compared via sodium dodecyl sulfatepolyacrylamide gel electrophoresis (SDS-PAGE) with identical protein loading quantities from individual $\mathrm{HDL}_{2}(3 \mu \mathrm{g}$ total protein per lane) and $\mathrm{HDL}_{3}(5 \mu \mathrm{g}$ total protein per lane), and the level of expression of apolipoprotein was analyzed via immunodetection. Goat anti-human apoA-I antibody (ab7613) was purchased from Abcam (Cambridge, UK) as a primary antibody. Anti-goat immunoglobulin G (SC2020; Santa Cruz Biotechnology, Inc., Santa Cruz, CA, USA) was used as the secondary antibody. The relative band intensity (BI) was compared via band scanning with Gel Doc ${ }^{\circledR}$ XR (Bio-Rad) using Quantity One software (version 4.5.2).

Transmission electron microscopy (TEM). TEM was performed with a Hitachi electron microscope (model H-7600; Ibaraki, Japan) operating at $80 \mathrm{kV}$, as in our previous report (28). VLDL, LDL, and HDL were negatively stained with $1 \%$ sodium phosphotungstate (PTA; $\mathrm{pH}$ 7.4) with a final apolipoprotein concentration of $0.3 \mathrm{mg} / \mathrm{ml}$ in TBS. Each lipoprotein, $5 \mu \mathrm{l}$ of a $0.3 \mathrm{mg} / \mathrm{ml}$ suspension, was blotted with filter paper and immediately replaced with a $5 \mu \mathrm{l}$ droplet of $1 \%$ PTA. After a few seconds, the stained lipoprotein fraction was blotted onto a Formvar carbon-coated 300 mesh copper grid and air-dried. The shape and size of lipoproteins were determined by TEM photography at a magnification of $x 40,000$.

Data analysis. All data are expressed as the mean \pm SD from at least three independent experiments with duplicate samples. Data comparisons were assessed by the Student's t-test using the SPSS program (version 14.0; SPSS, Inc., Chicago, IL, USA).

\section{Results}

Baseline characteristics. Although the AF group had a slightly higher BMI than the control group, there was no difference in the BMI and systemic blood pressure between the groups, and the BMIs and systemic blood pressures were in the normal range, as shown in Table I. No significant difference in the LVEF and LA dimension between the groups was detected, although the LA size was slightly larger in the AF group. The plasma levels of TC, TG, HDL-C, and LDL-C of the AF group were similar to the control group. There was no difference in the plasma CETP activity between the AF and control groups (Table I). Additionally, there were no differences in glucose, uric acid, creatinine, and blood urea nitrogen 
Table II. Lipid and protein compositions in lipoproteins.

\begin{tabular}{|c|c|c|c|c|c|c|}
\hline & \multicolumn{3}{|c|}{$\mathrm{AF}(\mathrm{n}=11)$} & \multicolumn{3}{|c|}{ Control $(n=10)$} \\
\hline & $\mathrm{TC}$ & TG & $\mathrm{TP}$ & $\mathrm{TC}$ & TG & $\mathrm{TP}$ \\
\hline VLDL (mg/ml) & $0.62 \pm 0.31$ & $0.55 \pm 0.28$ & $0.37 \pm 0.18$ & $0.52 \pm 0.24$ & $0.46 \pm 0.19$ & $0.31 \pm 0.12$ \\
\hline $\operatorname{Ratio}^{1}(\mathrm{mg} / \mathrm{mg})$ & $1.8 \pm 0.9$ & $1.64 \pm 0.84$ & 1.0 & $1.7 \pm 0.7$ & $1.47 \pm 0.63$ & 1.0 \\
\hline Total amount (mg) & $0.77 \pm 0.45$ & $0.69 \pm 0.48$ & $0.44 \pm 0.22$ & $0.64 \pm 0.32$ & $0.54 \pm 0.23$ & $0.40 \pm 0.16$ \\
\hline $\mathrm{LDL}(\mathrm{mg} / \mathrm{ml})$ & $1.23 \pm 0.46^{\mathrm{a}}$ & $0.12 \pm 0.07^{\mathrm{a}}$ & $0.59 \pm 0.16$ & $0.80 \pm 0.14$ & $0.05 \pm 0.06$ & $0.40 \pm 0.04$ \\
\hline Ratio (mg/mg) & $2.1 \pm 0.8$ & $0.21 \pm 0.13$ & 1.0 & $2.0 \pm 0.5$ & $0.13 \pm 0.15$ & 1.0 \\
\hline Total amount (mg) & $2.29 \pm 1.07$ & $0.20 \pm 0.12^{\mathrm{a}}$ & $1.09 \pm 0.42$ & $2.10 \pm 0.50$ & $0.15 \pm 0.19$ & $1.03 \pm 0.22$ \\
\hline $\mathrm{HDL}_{2}(\mathrm{mg} / \mathrm{ml})$ & $0.40 \pm 0.14$ & $0.11 \pm 0.05^{\mathrm{b}}$ & $0.44 \pm 0.17$ & $0.38 \pm 0.10$ & $0.06 \pm 0.03$ & $0.42 \pm 0.09$ \\
\hline Ratio (mg/mg) & $0.96 \pm 0.34$ & $0.29 \pm 0.17^{\mathrm{a}}$ & 1.0 & $0.89 \pm 0.24$ & $0.14 \pm 0.08$ & 1.0 \\
\hline Total amount (mg) & $0.20 \pm 0.23^{\mathrm{a}}$ & $0.13 \pm 0.07^{\mathrm{b}}$ & $0.48 \pm 0.22$ & $0.19 \pm 0.06$ & $0.03 \pm 0.01$ & $0.49 \pm 0.06$ \\
\hline $\mathrm{HDL}_{3}(\mathrm{mg} / \mathrm{ml})$ & $0.53 \pm 0.21$ & $0.11 \pm 0.03$ & $1.03 \pm 0.33$ & $0.50 \pm 0.16$ & $0.08 \pm 0.04$ & $0.89 \pm 0.17$ \\
\hline Ratio (mg/mg) & $0.56 \pm 0.22$ & $0.1 \pm 0.34$ & 1.0 & $0.57 \pm 0.18$ & $0.10 \pm 0.06$ & 1.0 \\
\hline Total amount (mg) & $0.65 \pm 0.28$ & $0.14 \pm 0.04$ & $1.20 \pm 0.28$ & $0.70 \pm 0.31$ & $0.12 \pm 0.06$ & $1.22 \pm 0.40$ \\
\hline
\end{tabular}

${ }^{\mathrm{a}} \mathrm{p}<0.05$ vs. control; ${ }^{\mathrm{b}} \mathrm{p}<0.01$ vs. control; $\mathrm{AF}$, atrial fibrillation; HDL, high-density lipoprotein; LDL, low-density lipoprotein; VLDL, very-lowdensity lipoprotein ; TC, total cholesterol; TG, triglyceride; TP, total protein; ${ }^{1}$ ratio vs. TP.

A

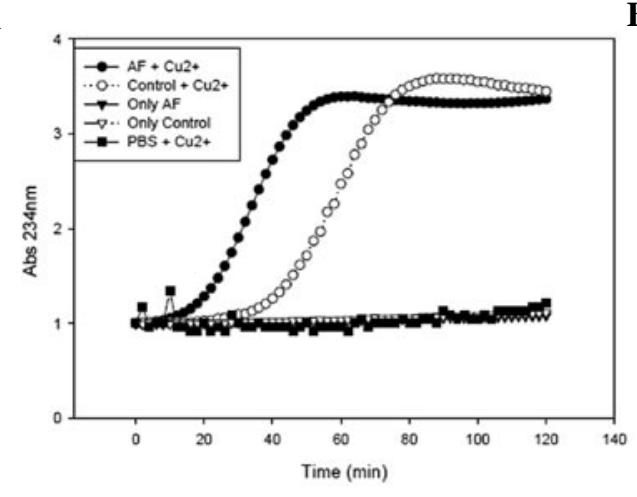

B

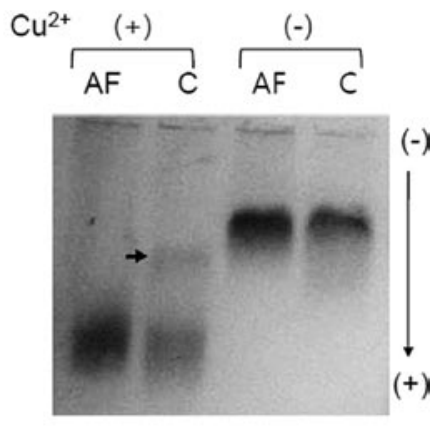

(0.5\% Agarose gel)
C

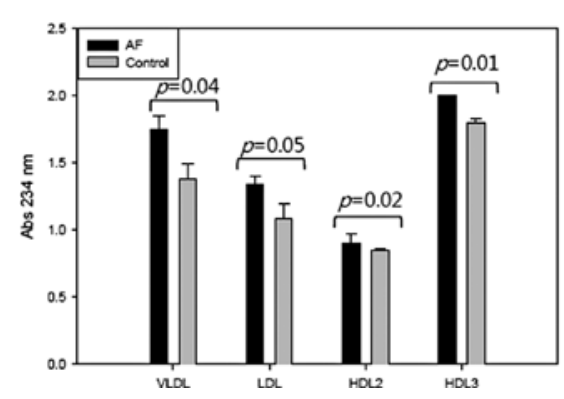

D

Lipoprotein MDA assay

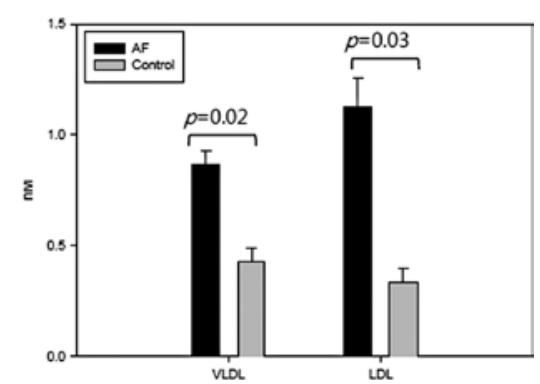

Figure 1. Comparison of the extent of oxidation in lipoproteins between the AF and control (C) groups. (A) Monitoring of conjugated diene level production in LDL $(0.3 \mathrm{mg} / \mathrm{ml})$ in the presence of $\mathrm{Cu}^{2+}$ (final concentration, $\left.10 \mu \mathrm{M}\right)$. (B) Electromobility of LDL from the AF and controls with or without treatment of $\mathrm{Cu}^{2+}$ (final concentration, $10 \mu \mathrm{M}$ ) for $6 \mathrm{~h}$. (C) Quantification of conjugated diene level in lipoproteins based on an equal protein amount between the patients with $\mathrm{AF}$ and controls (VLDL, $3 \mu \mathrm{g}$; LDL, $6 \mu \mathrm{g} ; \mathrm{HDL}_{2}, 6 \mu \mathrm{g}$; and $\mathrm{HDL}_{3}, 10 \mu \mathrm{g}$ of protein). (D) Determination of thiobarbituric acid reactive substances between the AF and control groups using malondialdehyde (MDA) as a standard. The same amount of protein was used between the group (VLDL, $0.15 \mathrm{mg} / \mathrm{ml}$; and LDL, $0.3 \mathrm{mg} / \mathrm{ml}$ of protein).

levels between the groups, indicating that carbohydrate metabolism and kidney function were normal. Although other inflammatory parameters (GOT and GPT) were at similar level between the groups, the AF group had a 7.5- and 6-fold 
A

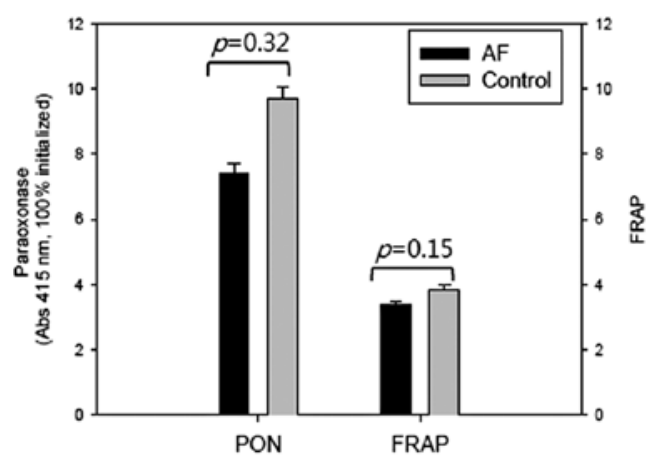

B

Ferric ion Reducing Ability of $\mathrm{HDL}$

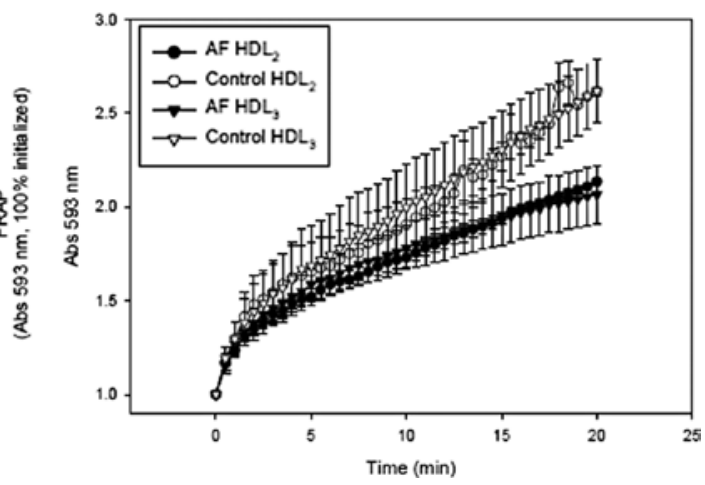

Figure 2. Comparison of antioxidant ability between the AF and control groups. (A) Plasma paraoxonase (PON) activity and ferric ion removal ability of plasma (FRAP). Twenty microliters of equally diluted plasma $(10 \mathrm{mg} / \mathrm{ml})$ was used as an enzyme source for 30 min of incubation. The error bars indicate the SD from three independent experiments with duplicate samples. (B) Ferric ion removal ability of HDL. Rate of increase in absorbance at $593 \mathrm{~nm}$. The HDL of the AF group had a much weaker reducing ability than the $\mathrm{HDL}_{3}$ of the control group during 20 min of incubation.

higher of hsCRP and troponin I, respectively, than the control group, suggesting the possibility that the AF group may have had myofibril damage with inflammation.

Lipoprotein properties. In patients with AF, VLDL and LDL were well-developed and enriched with cholesterol and TG, as shown in Table II. Especially with respect to LDL, the AF group had 25\% more enriched TG content than the control. $\mathrm{HDL}_{2}$ from patients with AF had a 4.3-fold increased TG content compared to controls. Based on the lipid/protein ratio, $\mathrm{LDL}$ and $\mathrm{HDL}_{2}$ from the AF group had a 1.5- and 1.7-fold increased TG/TP ratio, respectively, compared to the control group. However, there was no significant difference in the TC and $\mathrm{TG}$ content in $\mathrm{HDL}_{3}$ between the groups.

$A F-L D L$ was more sensitive to oxidation. Monitoring of the conjugated diene level revealed that the AF group had a $t_{1 / 2}$ max of 27 min, while the control group had a $t_{1 / 2} \max$ of $44 \mathrm{~min}$, as shown in Fig. 1A, suggesting that the LDL in patients with AF was 1.6-fold more sensitive to oxidation. Agarose electrophoresis revealed that the LDL samples from all of the patients with AF migrated to the bottom with darker intensity, while some of the LDL from the controls remained in the native state (as indicated by the arrow in Fig. 1B). These results indicate that cupric ion-mediated LDL oxidation was more sensitive in the AF group. However, there was no difference in the oxidation sensitivity of $\mathrm{HDL}_{2}$ and $\mathrm{HDL}_{3}$ between the groups (Fig. 1). UV quantification $(234 \mathrm{~nm})$ revealed that all lipoprotein fractions from the AF group contained more conjugated diene species, except $\mathrm{HDL}_{2}$, based on an equal amount of protein, as shown in Fig. 1C. Quantification of the oxidized species by TBARS using an MDA standard showed that AF-VLDL and AF-LDL contained a much higher content of MDA; AF-VLDL and AF-LDL were 2- and 3.3-fold higher than the control group, respectively (Fig. 1D).

Antioxidant potential. Plasma FRA ability and PON activity were decreased by $12 \%$ and $24 \%$ decreased, respectively, in the $\mathrm{AF}$ group compared to controls, as shown in Fig. 2A. Based on the same protein concentrations in the $\mathrm{HDL}_{2}$ and

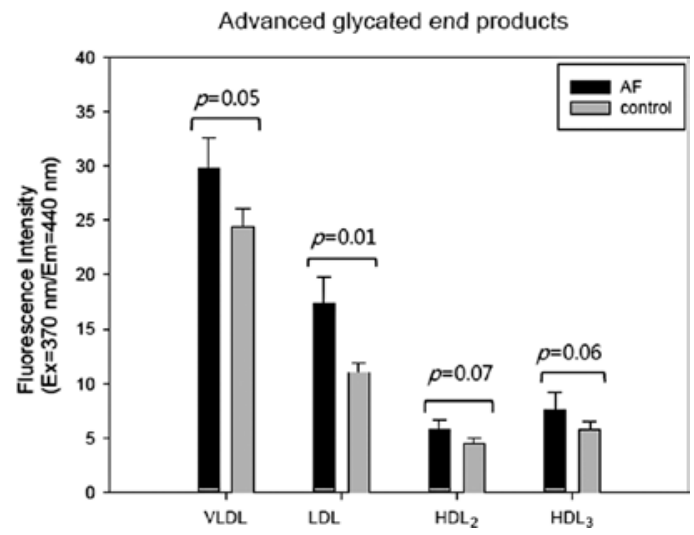

Figure 3. Quantification of advanced glycated end products. The extent of glycation was determined by fluorescence $(E x=370 \mathrm{~nm}, \mathrm{Em}=440 \mathrm{~nm})$ measurement in each lipoprotein fraction using the same amount of protein (VLDL, $15 \mu \mathrm{g}$; LDL, $32 \mu \mathrm{g}$; $\mathrm{HDL}_{2}, 30 \mu \mathrm{g}$; and $\mathrm{HDL}_{3}, 50 \mu \mathrm{g}$ ).

$\mathrm{HDL}_{3}$ fractions, the AF group had weaker ferric ion removal ability than the control group, as shown in Fig. 2B.

More glycated species in lipoproteins from the AF group. Fluorescence measurement revealed that all lipoprotein fractions from the AF group had a higher content of AGEs, as shown in Fig. 3. Specifically, VLDL and LDL from the AF group had a greater extent of glycation based on an equal amount of protein $(20 \%$ and $54 \%$ more content of AGE species than the control group, respectively).

Lower level of apoA-I in AF-HDL $L_{2}$. As shown in Fig. 4A, electrophoretic analysis of $\mathrm{HDL}_{2}$ and $\mathrm{HDL}_{3}$ revealed similar patterns of expression of apolipoproteins, except that the level of expression of apoA-I was much lower in the $\mathrm{HDL}_{2}$ fraction from patients with AF. Western blot analysis revealed that the average band intensities of apoA-I were $0.9 \pm 0.2$ and $1.3 \pm 0.1$ for the $\mathrm{HDL}_{2}$ fractions from patients with $\mathrm{AF}$ and controls, respectively $(\mathrm{p}=0.002)$; the level of expression of apoA-I was approximately $30 \%$ lower in the AF group than in controls. However, the level of immuno-detected apoA-I in the $\mathrm{HDL}_{3}$ fraction was similar between the groups; specifically, the average of the band 
A

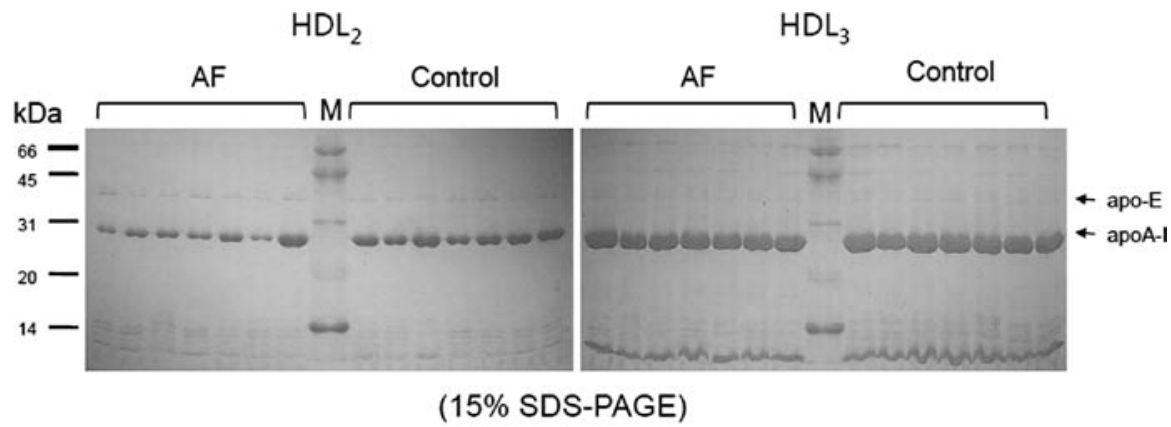

B

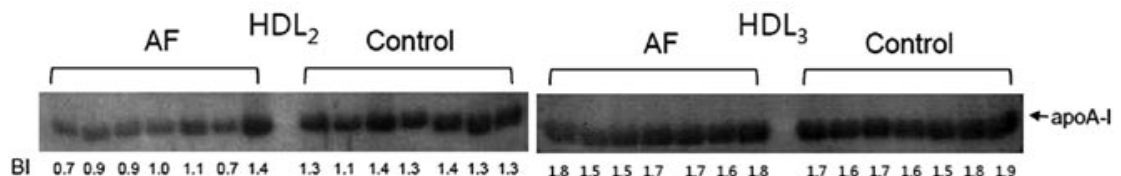

(Western blot)

Figure 4. Patterns of expression of apolipoproteins in HDL. (A) Electrophoretic patterns of $\mathrm{HDL}_{2}$ and $\mathrm{HDL}_{3}$ from the AF and control groups (15\% SDS-PAGE). Purified HDL via ultracentrifugation was equally diluted and the same amount of protein (3 $\mu \mathrm{g}$ for $\mathrm{HDL}_{2}$ and $5 \mu \mathrm{g}$ for $\left.\mathrm{HDL}_{3}\right)$ was loaded per lane and visualized by Coomassie blue staining. (B) Immunodetection of apoA-I in $\mathrm{HDL}_{2}$ and $\mathrm{HDL}_{3}$. Western blotting analysis with apoA-I antibody, which was raised by full-length apoA-I (ab7613; Abcam). The numbers below the blots indicate the relative band intensity (BI), which was analyzed using Gel Doc ${ }^{\circledR}$ XR (Bio-Rad).

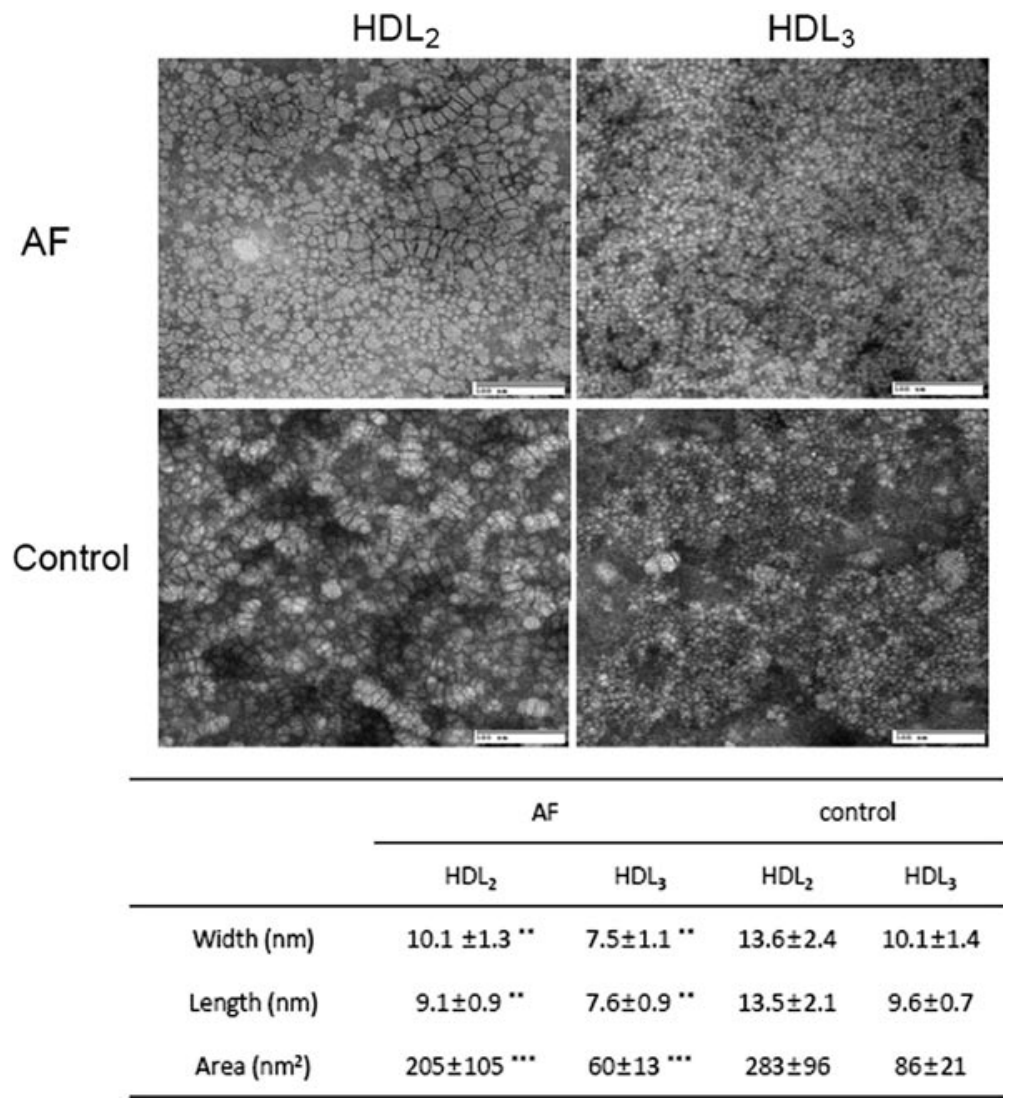

Figure 5. Representative photo of negatively-stained LDL, $\mathrm{HDL}_{2}$, and $\mathrm{HDL}_{3}$ from patients with $\mathrm{AF}$ and controls (electron microscopy). All micrographs are shown at a $\times 40,000$ magnification. The scale bar corresponds to $100 \mathrm{~nm}$. The table shows the dimensions and area of each HDL. ${ }^{* *} \mathrm{p}<0.01 \mathrm{vs}$. control; ${ }^{* * *} \mathrm{p}<0.005$ vs. control.

intensity (BI, indicated as the lower number) was approximately 1.6-1.7 for both groups, as shown in Fig. 4B.

Particle size of lipoproteins. Electron microscopy revealed that the AF group had a significantly smaller particle size of lipoproteins, as shown in Fig. 5. The LDL fraction from the patients with AF were 20 and $23 \mathrm{~nm}$ for width and length (W $x$ L), while the LDL fraction from controls were 24 and $25 \mathrm{~nm}$ for $\mathrm{W} \times \mathrm{L}$ (data not shown). The $\mathrm{HDL}_{2}(0.3 \mathrm{mg} / \mathrm{ml})$ and $\mathrm{HDL}_{3}$ fractions $(0.5 \mathrm{mg} / \mathrm{ml})$ from the $\mathrm{AF}$ group were 26-33\% smaller than the controls in $\mathrm{W} \times \mathrm{L}$. The size of the $\mathrm{HDL}_{2}$ fraction from the females with $\mathrm{AF}$ and controls using 

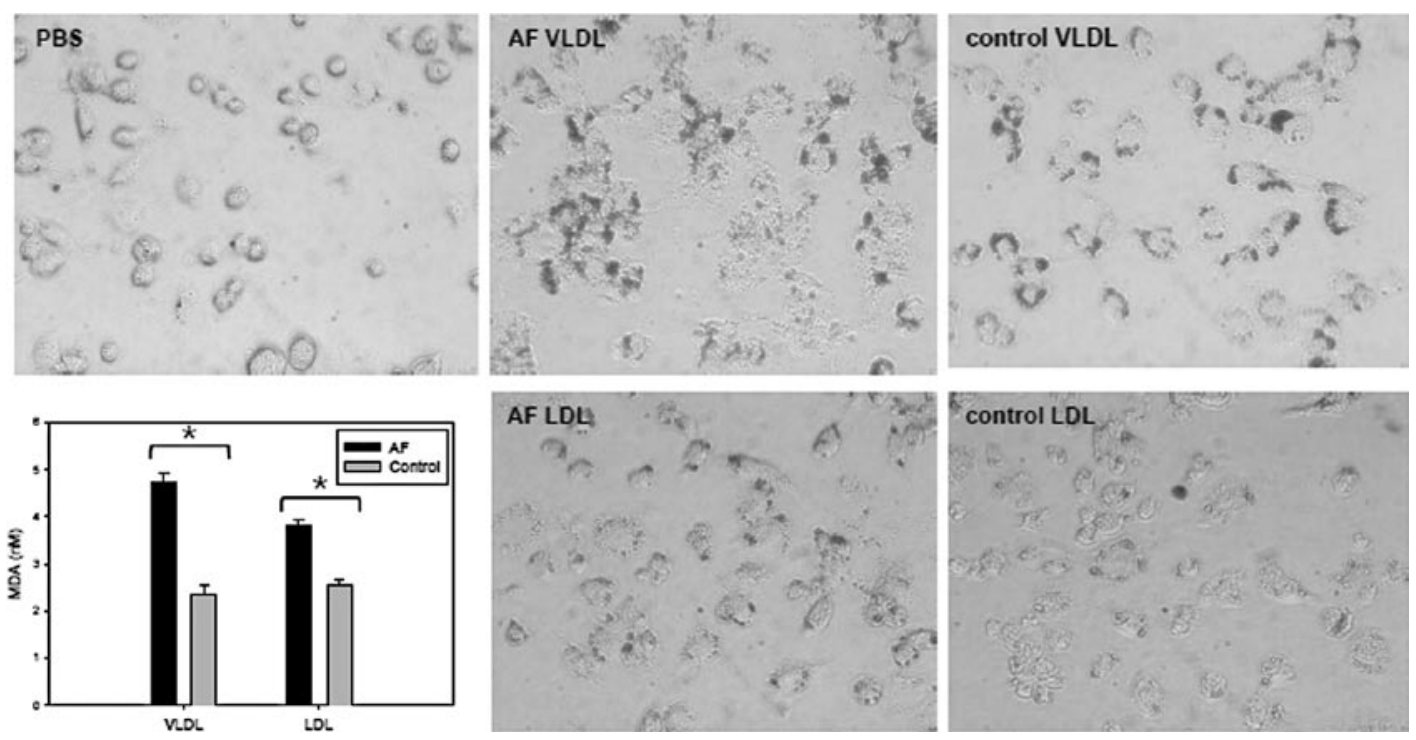

Figure 6. Cellular uptake of VLDL and LDL into macrophages. PMA differentiated THP-1 cells were incubated with $50 \mu 1$ of VLDL (0.15 mg/ml) or LDL $(0.33 \mathrm{mg} / \mathrm{ml})$ from the AF or control groups in the presence of $450 \mu \mathrm{l}$ of RPMI-1640 media. The extent of cellular uptake of the lipoproteins by macrophages was then compared by oil red O staining, as described in the text. The cells were then photographed using a Nikon Eclipse TE2000 microscope (Tokyo, Japan) at $\mathrm{x} 400$ magnification.

computer-assisted morphometry was $205 \pm 105 \mathrm{~nm}^{2}$ and $283 \pm 96 \mathrm{~nm}^{2}$, respectively; the size of the $\mathrm{HDL}_{3}$ fraction from patients with $\mathrm{AF}$ and controls was $60 \pm 13$ and $86 \pm 21 \mathrm{~nm}^{2}$, respectively. Thus, the size of the $\mathrm{HDL}_{2}$ and $\mathrm{HDL}_{3}$ fractions were reduced $28 \%$ and $31 \%$, respectively, which is in good agreement with the measurement of $\mathrm{W} \times \mathrm{L}$.

Acceleration of lipoprotein phagocytosis into macrophages. After a 48-h incubation, addition of VLDL (7.5 $\mu \mathrm{g}$ of protein) or LDL from patients with AF (16.5 $\mu \mathrm{g}$ of protein) into the cell medium resulted in a much stronger red intensity than the same amount of VLDL and LDL from controls, while PBS-treated cells did not exhibit red intensity, as shown in Fig. 6. This result indicates that VLDL and LDL from the AF group could be more easily taken up into macrophages by phagocytosis. Determination of the oxidized species within the culture media treated with the VLDL and LDL from patients with AF contained $4.7 \mathrm{nM}$ and $3.8 \mathrm{nM}$ of MDA, respectively, while media treated with VLDL and LDL from controls contained 2.3 and $2.5 \mathrm{nM}$ of MDA, respectively, as shown in Fig. 6. These results suggest that LDL from patients with $\mathrm{AF}$, which was more oxidized and glycated, accelerated the production of foam cells.

\section{Discussion}

Oxidative stress and inflammation have been linked to the pathogenesis and perpetuation of AF (2-4). Gene expression profiling on heart tissues from patients with AF suggest that oxidative stress-related genes are up-regulated. However, these findings are derived mostly from studies of chronic AF patients. The role of oxidative stress in paroxysmal lone AF is still unclear, and there have been no reports to compare the extent of oxidation and inflammation at the lipoprotein level. To identify this factor, we studied patients with paroxysmal lone AF who were remote from an episode of AF, thereby removing the effects of acute rate-related remodeling.
In the present study, we found that patients with paroxysmal lone AF had more oxidized (Fig. 1) and glycated (Fig. 3) lipoproteins with decreased plasma antioxidant ability (Fig. 2) and less apoA-I in $\mathrm{HDL}_{2}$ (Fig. 4). In addition, the AF group had smaller lipoprotein particle size (Fig. 5) and increased TG content (Table I) with accelerated foam cell formation (Fig. 6). Thus, we posit that these changes in lipoprotein profile and decreased antioxidant ability which occur in lone paroxysmal AF remotely from arrhythmia represent one of the essential contributors to the development of the initial substrate and progression of AF. The progression and perpetuation of AF may cause a vicious cycle which further makes the atrial substrate worse and susceptible to AF.

The occult abnormalities described in previous studies of paroxysmal lone AF were abnormal atrial histology, including patchy fibrosis (29), inflammation (30), and microvascular dysfunction in the coronary circulation (31). Stiles et al (32) stated that all of these features contributed to their observations of an abnormal substrate, the so-called 'second factor' in lone AF. We assume that these abnormalities, which we noted in the present study, may precede the occurrence of an abnormal substrate as a second factor as Stiles et al have reported (32).

Unlike in other cardiovascular diseases, AF patients did not show notable dyslipidemia in the current or in another study (12). Patients with paroxysmal lone AF have similar blood pressures serum cholesterol, HDL-C, LDL-C, TG, and fasting glucose levels; however, inflammatory parameters are increased in AF patients (33). Similarly, Zhang et al (34) reported that vascular cell adhesion molecule (VCAM)-1, hsCRP, and urotensin-II levels were significantly elevated in patients with paroxysmal lone AF. A Framingham offspring cohort study revealed that CRP and fibrinogen are elevated in the AF group (35). The cumulative evidence suggests that oxidative stress in myofibrils is directly associated with the incidence of AF (36). In this report, we showed that the AF 
group exhibited more oxidized VLDL and LDL with acceleration of foam cell production than the control group.

The oxidative modification of LDL, which is considered to be a strong risk factor for atherosclerosis and ACS, occurs through the release of pro-inflammatory and oxidative signals. The AF group also showed less PON activity and antioxidant potential in the HDL fraction (Fig. 2). Reduced PON activity is associated with a higher prevalence of CAD and arrhythmias in patients with myocardial infarction and ST-elevation (37). In general, the PON1 enzyme is physically associated with the $\mathrm{HDL}_{3}$ fraction and most of the PON activity exists in the $\mathrm{HDL}_{3}$ fraction, as well as other antioxidant enzymes (38). PON1 attenuates the oxidation of LDL via inhibition of the accumulation of lipid peroxides in LDL (39). The LDLs from the AF group were more easily oxidized by cupric ion treatment and had a higher content of oxidative stress (Fig. 1 and 2). Although more evidence is required to make concrete conclusions, the current results suggest that more highly oxidized lipoproteins might be a reason for $\mathrm{AF}$ rather than a result of AF.

Because there have been no reports to compare the extent of oxidation and inflammation in the lipoprotein level, we characterized the lipoprotein properties in female patients with AF in the current study. AF patients had more oxidized and glycated VLDL and LDL and an increased level of TG content (Table II) in LDL and $\mathrm{HDL}_{2}$, although the blood level of TG was in the normal range (Table I). It has been well-established that the serum TG level is an independent risk factor for CAD (40) and metabolic syndrome (41). The current study and other studies have suggested that TG-rich lipoproteins are pro-atherogenic and more specific to myocardial infarction (25), as well as to metabolic syndrome (42). The presence of increased TG in lipoproteins is in good agreement with the results of previous studies that indicated that TG levels are an important and independent predictor of CAD and stroke risk in the Asia-Pacific region (43). Furthermore, VLDL and LDL from the AF group, which were more oxidized and glycated, and had a smaller particle size, exhibited increased facilitated phagocytosis into macrophages with increased production of oxidized species (Fig. 6). These results are in good agreement with previous reports that TG-rich lipoproteins are pro-atherogenic (44) and TG-enriched VLDL are toxic to endothelial cells (45).

The apolipoproteins, apoA-I and apo-B, are the primary protein constituents of HDL and LDL, respectively. In the healthy state, HDL exerts many beneficial effects for the maintenance of a healthy physiological system, including antioxidant, anti-inflammatory, and anti-thrombotic effects (15). The AF patients in this study showed significantly lowered apoA-I levels in the $\mathrm{HDL}_{2}$ fraction (Fig. 4), indicating a reduced antioxidant potential. LDL is the major cholesterol carrier in the plasma with a heterogeneous particle size and composition. Small dense LDL, which is easily oxidized and glycated via interaction with reactive oxygen species and carbohydrate in the blood, are increased with progression of aging, diabetes mellitus, and CAD (46). The patients with AF in this study had smaller LDL and HDL particle sizes (Fig. 5), and AF-LDL was more easily taken up by macrophages (Fig. 6). Furthermore, the VLDL and LDL from patients with AF were more highly glycated (Fig. 3). These modifications of LDL particle size and extent of glycation are in good agreement with a previous report that small dense LDL is more preferentially glycated (47). In addition, more highly glycated LDL increases CC chemokine receptor-2 expression in macrophages and monocyte chemoattractant protein-1 mediated chemotaxis (48). Moreover, our research group recently reported an elevated level of LDL glycation in an elderly group (mean age, $71 \pm 4$ years), which had a higher inflammatory profile with a loss of antioxidant ability (49).

In conclusion, we have shown that the lipoprotein properties of AF patients are more oxidized and modified with a smaller particle size compared to controls. VLDL and LDL promoted more foam cell formation via accelerated phagocytosis of macrophages. $\mathrm{HDL}_{2}$ from the $\mathrm{AF}$ group had a lower apoA-I content and smaller particle size with decreased antioxidant ability. All of these modified properties, including oxidation and glycation of lipoproteins, might be connected to lowered antioxidant ability and elevated inflammatory parameters in the blood of patients with AF.

\section{Acknowledgements}

This work was supported by the National Research Foundation (NRF) through the Aging-associated Vascular Disease Research Center at Yeungnam University [R13-2005-005-01003-0 (2010)] and Undergraduate Research Program (2010-2-101) of Korea Foundation for the Advancement of Science and Creativity.

\section{References}

1. Go AS, Hylek EM, Phillips KA, Chang Y, Henault LE, Selby JV and Singer DE: Prevalence of diagnosed atrial fibrillation in adults: national implications for rhythm management and stroke prevention: the AnTicoagulation and Risk Factors in Atrial Fibrillation (ATRIA) Study. JAMA 285: 2370-2375, 2001.

2. Dudley SC Jr, Hoch NE, McCann LA, Honeycutt C, Diamandopoulos L, Fukai T, Harrison DG, Dikalov SI and Langberg J: Atrial fibrillation increases production of superoxide by the left atrium and left atrial appendage: role of the NADPH and xanthine oxidases. Circulation 112: 1266-1273, 2005.

3. Kim YM, Guzik TJ, Zhang YH, Zhang MH, Kattach H, Ratnatunga C, Pillai R, Channon KM and Casadei B: A myocardial Nox 2 containing $\mathrm{NAD}(\mathrm{P}) \mathrm{H}$ oxidase contributes to oxidative stress in human atrial fibrillation. Circ Res 97: 629-636, 2005.

4. Neuman RB, Bloom HL, Shukrullah I, Darrow LA, Kleinbaum D, Jones DP and Dudley SC Jr: Oxidative stress markers are associated with persistent atrial fibrillation. Clin Chem 53: 1652-1657, 2007.

5. Steinberg D: Atherogenesis in perspective: hypercholesterolemia and inflammation as partners in crime. Nat Med 8: 1211-1217, 2002.

6. Clarkson CW and Ten Eick RE: On the mechanism of lysophophatidylcholine-induced depolarization of cat ventricular myocardium. Circ Res 52: 543-556, 1983.

7. Pogwizd SM, Onufer JR, Kramer JB, Sobel BE and Corr PB: Induction of delayed after depolarizations and triggered activity in canine Purkinje fibers by lysophosphoglycerides. Circ Res 59: 416-426, 1986.

8. Adamantidis MM, Moreau-Guedon L, Martin-Nizard F, SqalliHoussaini H, Duriez P, Fruchart JC and Dupuis B: Oxidized low density lipoproteins exert arrhythmogenic effects in rabbit Purkinje fibers. Biochem Biophys Res Comm 182: 548-554, 1992.

9. Chen YJ, Chen SA, Chen YC, Yeh HI, Chan P, Chang MS and Lin CI: Effects of rapid atrial pacing on the arrhythmogenic activity of single cardiomyocytes from pulmonary veins: implication in initiation of atrial fibrillation. Circulation 104: 2849-2854, 2001

10. Grundy SM: Role of low-density lipoproteins in atherogenesis and development of coronary heart disease. Clin Chem 41: 139-146, 1995. 
11. Garvey WT, Kwon S, Zheng D, Shaughnessy S, Wallace P, Hutto A, Pugh K, Jenkins AJ, Klein RL and Liao Y: Effects of insulin resistance and type 2 diabetes on lipoprotein subclass particle size and concentration determined by nuclear magnetic resonance. Diabetes 52: 453-462, 2003.

12. Kannel WB, Wolf PA, Benjamin EJ and Levy D: Prevalence, incidence, prognosis, and predisposing conditions for atrial fibrillation: population-based estimates. Am J Cardiol 82: 2N-9N, 1998.

13. Expert Panel on Detection, Evaluation, and Treatment of High Blood Cholesterol in Adults: Executive Summary of The Third Report of The National Cholesterol Education Program (NCEP) Expert Panel on Detection, Evaluation, And Treatment of High Blood Cholesterol In Adults (Adult Treatment Panel III). JAMA 285: 2486-2497, 2001

14. Tousoulis D, Zisimos K, Antoniades C, Stefanadi E, Siasos G, Tsioufis C, Papageorgiou N, Vavouranakis E, Vlachopoulos C and Stefanadis C: Oxidative stress and inflammatory process in patients with atrial fibrillation: the role of left atrium distension. Int J Cardiol 136: 258-262, 2009.

15. Barter PJ, Nicholls S, Rye KA, Anantharamaiah GM, Navab M and Fogelman AM: Antiinflammatory properties of HDL. Circ Res 95: 764-772, 2004.

16. Lewis GF and Rader DJ: New insights into the regulation of HDL metabolism and reverse cholesterol transport. Circ Res 96 1221-1232, 2005

17. Fuster V, Rydén LE, Cannom DS, Crijns HJ, Curtis AB, Ellenbogen KA, Halperin JL, Le Heuzey JY, Kay GN, Lowe JE, Olsson SB, Prystowsky EN, Tamargo JL, Wann S, Smith SC Jr, Jacobs AK, Adams CD, Anderson JL, Antman EM, Halperin JL, Hunt SA, Nishimura R, Ornato JP, Page RL, Riegel B, Priori SG, Blanc JJ, Budaj A, Camm AJ, Dean V, Deckers JW, Despres C, Dickstein K, Lekakis J, McGregor K, Metra M, Morais J, Osterspey A, Tamargo JL and Zamorano JL; American College of Cardiology/American Heart Association Task Force on Practice Guidelines; European Society of Cardiology Committee for Practice Guidelines; European Heart Rhythm Association; Heart Rhythm Society: ACC/AHA/ESC 2006 guidelines for the management of patients with atrial fibrillation: executive summary: a report of the American College of Cardiology/ American Heart Association Task Force on Practice Guidelines and the European Society of Cardiology Committee for Practice Guidelines and Policy Conferences (Writing Committee to Revise the 2001 Guidelines for the Management of Patients With Atrial Fibrillation). Circulation 114: e257-e354, 2006.

18. Havel RJ, Eder HA and Bragdon JH: The distribution and chemical composition of ultracentrifugally separated lipoproteins in human serum. J Clin Invest 34: 1345-1353, 1995.

19. Markwell MA, Haas SM, Bieber LL and Tolbert NE: A modification of the Lowry procedure to simplify protein determination in membrane and lipoprotein samples. Anal Biochem 87: 206-210, 1978.

20. Blois MS: Antioxidant determination by the use of a stable free radicals. Nature 181: 1199-2000, 1958

21. Park KH, Jang W, Kim KY, Kim JR and Cho KH: Fructated apolipopretein A-I showed severe structural modification and loss of beneficial functions in lipid-free and lipid-bound state with acceleration of atherosclerosis and senescence. Biochem Biophys Res Commun 392: 295-300, 2010.

22. Esterbauer H, Striegl G, Puhl H and Rotheneder M: Continuous monitoring of in vitro oxidation of human low density lipoprotein. Free Radic Res Commun 6: 67-75, 1989.

23. Noble RP: Electrophoretic separation of plasma lipoproteins in agarose gel. J Lipid Res 9: 693-700, 1968.

24. Benzie IF and Strain JJ: The ferric reducing ability of plasma (FRAP) as a measure of antioxidant power: the FRAP assay. Anal Biochem 239: 70-76, 1996

25. Cho KH, Shin DG, Baek SH and Kim JR: Myocardial infarction patients showed altered lipoprotein properties and functions when compared with stable angina pectoris patients. Exp Mol Med 41: 67-76, 2009.

26. Cho KH: Synthesis of reconstituted high-density lipoprotein (rHDL) containing apoA-I and apoC-III: the functional role of apoC-III in rHDL. Mol Cells 27: 291-297, 2009.

27. Eckerson HW, Wyte CM and La Du BN: The human serum paraoxonase/arylesterase polymorphism. Am J Hum Genet 35: $1126-1138,1983$.

28. Cho KH, Park JE, Kim YO, Choi I, Kim JJ and Kim JR: The function, composition, and particle size of high-density lipoprotein were severely impaired in an oliguric phase of hemorrhagic fever with renal syndrome. Clin Biochem 41: 56-64, 2008.
29. Frustaci A, Chimenti C, Bellocci F, Morgante E, Russo MA and Maseri A: Histological substrate of atrial biopsies in patients with lone atrial fibrillation. Circulation 96: 1180-1184, 1997.

30. Chung MK, Martin DO, Sprecher D, Wazni O, Kanderian A, Carnes CA, Bauer JA, Tchou PJ, Niebauer MJ, Natale A and Van Wagoner DR: C-reactive protein elevation in patients with atrial arrhythmias: inflammatory mechanisms and persistence of atrial fibrillation. Circulation 104: 2886-2891, 2001.

31. Skalidis EI, Hamilos MI, Karalis IK, Chlouverakis G, Kochiadakis GE and Vardas PE: Isolated atrial microvascular dysfunction in patients with lone recurrent atrial fibrillation. J Am Coll Cardiol 51: 2053-2057, 2008

32. Stiles MK, John B, Wong CX, Kuklik P, Brooks AG, Lau DH, Dimitri H, Roberts-Thomson KC, Wilson L, De Sciscio P, Young GD and Sanders P: Paroxysmal lone atrial fibrillation is associated with an abnormal atrial substrate: characterizing the 'second factor'. J Am Coll Cardiol 53: 1182-1191, 2009.

33. Roldán V, Marín F, Blann AD, García A, Marco P, Sogorb F and Lip GY: Interleukin-6, endothelial activation and thrombogenesis in chronic atrial fibrillation. Eur Heart J 24: 1373-1380, 2003.

34. Zhang L, Ding R, Zhen Y and Wu ZG: Relation of urotensin II levels to lone atrial fibrillation. Am J Cardiol 104: 1704-1707, 2009.

35. Schnabel RB, Larson MG, Yamamoto JF, Sullivan LM, Pencina MJ, Meigs JB, Tofler GH, Selhub J, Jacques PF, Wolf PA, Magnani JW, Ellinor PT, Wang TJ, Levy D, Vasan RS and Benjamin EJ: Relations of biomarkers of distinct pathophysiological pathways and atrial fibrillation incidence in the community. Circulation 121: 200-207, 2010.

36. Mihm MJ, Yu F, Carnes CA, Reiser PJ, McCarthy PM, Van Wagoner DR and Bauer JA: Impaired myofibrillar energetics and oxidative injury during human atrial fibrillation. Circulation 104: 174-180, 2001.

37. Hicks JJ, Montes-Cortes DH, Cruz-Dominguez MP, MedinaSantillan R and Olivares-Corichi IM: Antioxidants decrease reperfusion induced arrhythmias in myocardial infarction with ST-elevation. Front Biosci 12: 2029-2037, 2007.

38. Yoshikawa M, Sakuma N, Hibino T, Sato T and Fujinami T: HDL3 exerts more powerful anti-oxidative, protective effects against copper-catalyzed LDL oxidation than HDL2. Clin Biochem 30: 221-225, 1997.

39. Mackness MI, Arrol S and Durrington PN: Paraoxonase prevents accumulation of lipoperoxides in low-density lipoprotein. FEBS Lett 286: 152-154, 1991 .

40. McBride PE: Triglycerides and risk for coronary heart disease. JAMA 298: 336-338, 2007.

41. Park KH, Shin DG, Kim JR and Cho KH: The functional and compositional properties of lipoproteins are altered in patients with metabolic syndrome with increased cholesteryl ester transfer protein activity. Int J Mol Med 25: 129-136, 2010.

42. Libby P: Fat fuels the flame triglyceride-rich lipoproteins and arterial inflammation. Circulation 100: 299-301, 2007.

43. Patel A, Barzi F, Jamrozik K, Lam TH, Ueshima H, Whitlock G, Woodward M; Asia Pacific Cohort Studies Collaboration: Serum triglycerides as a risk factor for cardiovascular diseases in the Asia-Pacific region. Circulation 110: 2678-2686, 2004.

44. Ginsberg HN: New prospectives on atherogenesis: role of abnormal triglyceride-rich lipoprotein metabolism. Circulation 106: 2137-2142, 2002

45. Gianturco SH, Eskin SG, Navarro LT, Lahart CJ, Smith LC and Gotto AM Jr: Abnormal effects of hypertriacylglycerolemic very low-density lipoproteins on 3-hydroxy-3-methyl-glutaryl-CoA reductase activity and viability of cultured bovine aortic endothelial cells. Biochim Biophys Acta 618: 143-152, 1980.

46. Gardner CD, Fortmann SP and Krauss RM: Association of small low-density lipoprotein particles with the incidence of coronary artery disease in men and women. JAMA 276: 875-881, 1996.

47. Younis N, Charlton-Menys V, Sharma R, Soran H and Durrington PN: Glycation of LDL in non-diabetic people: Small dense LDL is preferentially glycated both in vivo and in vitro. Atherosclerosis 202: 162-168, 2009.

48. Isoda K, Folco E, Marwali MR, Ohsuzu F and Libby P: Glycated LDL increases monocyte $\mathrm{CC}$ chemokine receptor 2 expression and monocyte chemoattractant protein-1-mediated chemotaxis. Atherosclerosis 198: 307-312, 2008.

49. Park KH, Shin DG, Kim JR and Cho KH: Senescence-related truncation and multimerization of apolipoprotein A-I in highdensity lipoprotein with an elevated level of advanced glycated end products and cholesteryl ester transfer activity. J Gerontol A Biol Sci Med Sci 65: 600-610, 2010. 